\title{
Prevalence and Associated Factors of Adverse Birth Outcome Among Deliveries at Butajira Hospital, Southern Ethiopia
}

Ritbano Ahmed Abdo*, Hassen Mossa Halil, Lealem Zerihun Birhanu, Dejene Agero Defara and Biruk Assefa Kebede

Department of Midwifery, Wachemo University, Ethiopia

Submission: June 20, 2019 ; Published: July 01, 2019

*Corresponding author: Ritbano Ahmed Abdo, Department of Midwifery, Wachemo University, Ethiopia

Summary

Background: Adverse birth outcomes are the most common public health problem in both developed and developing countries, including Ethiopia.

Objective: This study aimed to assess the prevalence and associated factors of adverse birth outcome among deliveries at Butajira Hospital, Southern Ethiopia.

Methods: An institution-based cross-sectional study was conducted from February 1- 21, 2019 at Butajira Hospital. Three hundred thirteen mothers' card was obtained using the systematic sampling method. A pre-tested checklist was used to collect data. Data were entered into Epidata version 3.1 and analyzed using SPSS version 22. Multiple logistic regression was used to identify associated factors of adverse birth outcome with $95 \% \mathrm{CI}$ and P value $<0.05$.

Result: The overall prevalence of adverse birth outcome was 18.2\%. The factors significantly associated with the adverse birth outcome were as follows: being rural residence $[\mathrm{AOR}=3.2 ; 95 \% \mathrm{CI}(1.5,7.7)]$, mothers aged 35 and above $[\mathrm{AOR}=8.7 ; 95 \% \mathrm{CI}(3.1,24.5)]$, history of abortion [AOR=2.4; 95\%CI $(1.1,5.4)]$, and pregnancy complication $[\mathrm{AOR}=12.9 ; 95 \% \mathrm{CI}(4.8,35.2)]$.

Conclusion and recommendation: Adverse birth outcome is quite common in the study area. Mothers aged 35 and above, being rural residence, pregnancy complication, and history of abortion were associated factors of adverse birth outcome. Health education during antenatal follow-up of pregnant mothers about the need to attend maternity ward early, as soon as possible during labor recommended to reduce adverse birth outcome.

Keywords: Prevalence; Adverse birth outcome; Associated Factors; Southern Ethiopia

Abbreviations: ANC: Antenatal Care; AOR: Adjusted Odd Ratio; CI: Confidence Interval; SPSS: Statistical Package for Social Science; UTI: Urinary Tract Infection; HIV: Human Immunodeficiency Viruses

\section{Introduction}

Over the last two decades, the world made substantial progress in reducing mortality among children. Despite of these in 2017 alone, an estimated 5.4 million under age 5 died, mostly from preventable causes. Neonatal deaths account for a greater, and growing, share of all deaths among children younger than 5 [1]. An estimated 2.5 million newborns died in the first month of life -approximately 7,000 every day-most of whom died in the first week after birth. About 36\% died the same day they were born, and close to three-quarters of all newborn deaths in 2017 occurred in the first week of life [2]. It accounts for about half (47\%) of under-five child deaths [1-3]. The major causes of neonatal deaths are complications of prematurity, intrapartum-related deaths, and severe neonatal infections $[4,5]$. Adverse birth outcome is a common and serious health problem globally. The rate of adverse birth outcomes has been increasing worldwide, including developed countries [3]. Preterm birth and low birth weight infants are at greater risk for mortality and a variety of health and developmental problems [6].

Preterm birth is defined as a live birth before 37 completed weeks of gestation [7]. Globally, 15(9.5\%) million babies are 
born too soon every year and more than $3 / 4$ occur in Africa and South Asia and this number is increasing. Over 1 million (35\%) children die each year due to complication of preterm birth. It is leading cause of newborn deaths and now the second leading cause of death after pneumonia in children under the age of 5 $[3,8]$. Many survivors face a short term complications such as acute respiratory, gastrointestinal, immunologic, and central nervous system problems and long-term effects of preterm birth, including motor, cognitive, visual, hearing, behavioral, social-emotional, health, and growth problems, may not become apparent for years and may persist throughout a child's life into adulthood [9].

Low birth weight is defined as weight at birth less than $2500 \mathrm{~g}$ (5.5lb) [7]. Low birth weight continues to be a significant public health problem globally and is associated with a range of both short-and long-term consequences. Overall, it is estimated that $15 \%$ to $20 \%$ of all births worldwide are low birth weight babies, representing more than 20 million births a year. The great majority of low birth weight births occur in low- and middle-income countries $[10,11]$. Low birth weight increases the risk for non-communicable diseases such as diabetes and cardiovascular disease later in life $[12,13]$. The consequences of low birth weight also include fetal, neonatal mortality and morbidity, poor cognitive development [14-16] and an increased risk of chronic diseases later in life [17].

A stillbirth is the birth of a newborn after $28^{\text {th }}$ completed week (weighing $1000 \mathrm{~g}$ or more) when the baby does not breathe or show any sign of life after delivery. Such deaths include antepartum deaths (macerated) and intrapartum deaths [7]. It is a shocking event that has considerable impacts on those affected [18-20]. In every year, 2.6 million Stillbirths occur worldwide and 1.2 million occur after the onset of labour and congenital anomalies accounts for 9\% neonatal death [21]. Furthermore, the adverse birth outcomes can have significant emotional and economic effects on the infant's family $[19,22,23]$.

There have been a number of previous studies trying to identify associated factors of adverse birth outcome in several countries. However, the factors associated with adverse birth outcome are not the same across different cultures and socioeconomic statuses within a society. Recognized sociodemographic factors for adverse birth outcome rural resident $[24,25]$, low level of maternal education [7,26-28], age of the mother less than $20[24,28]$ and age of the mother $(\geq 35)$ years [29]. Obstetric factors include primipara, unwanted pregnancy, previous history of adverse birth outcome [30], pregnancy complication [25,28,31-33], premature rupture of membrane [28], induced onset of labor [9,30], no-antenatal care visit [33] and incomplete antenatal visit. In addition, studies revealed that, the presence of chronic disease/s [27,30], inadequate maternal age gain during pregnancy $[7,26,27]$ and maternal anemia [32] were factors of adverse birth outcome. As studies indicated, the prevalence of adverse birth outcome varies from place to place in
Ethiopia. Prevalence of adverse birth outcome in different towns of Ethiopia is in a range of $18.3 \%-32.5 \%$ [29,31-34].

In Ethiopia, national reproductive health strategy 20142018 are developed in 2014 and have implemented a number of activities to improve birth outcomes are increased midwives and emergency surgeons, equip health center with basic obstetrics and newborn care equipments, equip all hospitals to provide comprehensive obstetrics and newborn care, improving antenatal care and promoting institutional delivery, ensure availability of medicines, supplies and equipments for antenatal care follow up, childbirth, postpartum and newborn care, improving referral system and health care financing [35].

However, adverse birth outcome seems to be a common cause of neonatal morbidity and mortality in Ethiopia. About 258 stillbirths (30 per 1,000 total births) occur every day [36] and 320,000 babies are born too soon each year and 23,100 children under five die due to direct preterm birth complications [37]. Hospital based studies conducted in Ethiopia show a high neonatal death due to preterm birth [38,39]. Furthermore, congenital anomalies are also another major contributor of neonatal death in Ethiopia (11.7\%) [38]. Therefore, the need for further study is absolute to recognize the prevalence and associated factors of adverse birth outcome.

\section{Methods}

\section{Study Area and Period}

It was an institution-based cross-sectional employed in Butajira Zonal hospital from March 6-27, 2019. Butajira is located at $135 \mathrm{Kms}$ to south of Addis Ababa and $162 \mathrm{kms}$ from Hawassa. It is arbitrarily bordered by Sodo District in the north, Silti District in south, Mareko District in the east and Muhireaklil District in the west. Butajira town covers a total area of 1854.24 hectares and the total population is 49,121 people among them 24,069 are male and 25,052 are female. The town has 7 health institutions, including private clinics among them four are governmental health institutions. The source populations for the study were all cards for mothers who gave birth at Butajira hospital from February 1, 2018 to February 1, 2019. Study populations were randomly selected cards for mothers who gave birth at Butajira hospital from February 1, 2018 to February 1, 2019.

The sample size was determined by using the single population proportion formula. The following assumptions were used to estimate the sample size; the proportion of adverse birth outcome was taken from the study conducted at Negest Elene Mohammed Memorial General Hospital in Hossana Town (24.5\%) (32), with 95\% confidence interval and desired precision $5 \%$ and $10 \%$ missed item rate, the final sample size was 313 mothers' cards. Three hundred thirteen mother's cards were obtained using the systematic sampling technique. First, the sample frame was developed using maternity registration numbers from February 1, 2018 to February 1, 2019. Then interval was calculated by dividing total deliveries from February 
1, 2018 to February 1, 2019. The first number was selected by using a lottery method from the first 10 maternal registration numbers. Finally, subjects (cards) were selected at every 10 interval and using selected card numbers of the mothers, the card was retrieved from the card room. Data were collected by using a pre-tested checklist from maternal cards. The checklist was developed based on instruments that were applied in other related studies [32-35]. The checklist was designed to collect data on socio-demographic variables, Obstetric related characteristics and medical illness. Data were collected by four clinical nurses. To ensure the quality of data were collected from the mothers card, first, a data collection instrument was pretested on 16 maternity records for the year 2017 and was modified to correct observed inconsistencies. Also, data collectors were discussed on procedures of data collection techniques before data collection begun. In addition, at the end of each day collected data were reviewed, and accuracy and consistency by the investigators and corrective measure was undertaken.

\section{Operational Definition of Variable}

Adverse birth outcome: a mother who gave us- low birth weight, preterm, congenital malformation or/and stillbirth, and was classified as: "yes" or "no.

Pregnancy during: a mother who developed as-Antepartum hemorrhage, Pregnancy induced hypertension (gestational, preeclampsia or eclampsia), Polyhydramnios, chorioamnionitis or/ and others.

Labour Complication: defined as mothers with at least any one of malpresentation, malposition, prolonged labour or obstructed labour, or/and others, (Present=1 or absent=0).

\section{Data Analysis Procedure}

Data were entered using Epi-data version 3.1 and exported to Statistical Package social science (SPSS), version 21.0 software for analyses. Descriptive statistics such as number, percent, mean and standard deviation were used to summarize and present major findings. Binary logistic regression analysis was used to identify factors associated with adverse birth outcome. First a bivariate logistic regression was carried out to select candidate for multiple logistic regression analysis. Variable with p-value less than 0.25 in the bivariate logistic regression was selected for multiple logistic regression. Multiple logistic regression was done for variables that has $\mathrm{p}$-value $<0.25$ during the bivariate logistic regression analyses to identify factors associated with adverse birth outcome. The degree of association between independent and dependent variables were assessed using Table 2: Obstetric related characteristics of mothers who were gave birth odds ratio with $95 \%$ confidence interval. The P-value $<0.05$ was considered as statistically significant. The Hosmer-Lemeshow statistic had significant value of 0.65 which shows that it is not statistically significant so that the model was a good fit. Formal letter of permission was obtained from the Wachemo University College of medicine and Health sciences. In addition, a letter of permission was secured from Butajira town health office and Hospitals Management Committee. Confidentiality of information was maintained.

\section{Result}

\section{Sociodemographic Characteristics}

Regarding to the Sociodemographic characteristics of the mothers, $249(79.6 \%)$ were in the age group of 20-34. The majority of them were urban $309(98.7 \%)$ and married $214(68.4 \%)$ by residence and marital status respectively (Table 1).

Table 1: Sociodemographic characteristics of mothers who were gave birth at Butajira Hospital from February 1, 2018 to February 1, 2019.

\begin{tabular}{|c|c|c|}
\hline Variable & Frequency $(\mathrm{N}=313)$ & Percent \\
\hline \multicolumn{3}{|c|}{ Age Group } \\
\hline$<20$ & 33 & 10.5 \\
\hline $20-34$ & 249 & 79.6 \\
\hline $35 \&$ above & 31 & 9.9 \\
\hline \multicolumn{3}{|c|}{ Residency } \\
\hline Urban & 214 & 68.4 \\
\hline Rural & 99 & 31.6 \\
\hline \multicolumn{3}{|c|}{ Marital Status } \\
\hline Married & 309 & 98.7 \\
\hline Others & 4 & 1.3 \\
\hline
\end{tabular}

Concerning gravidity, 223(71.2\%) mothers were multigravida. sixty-nine $(22 \%)$ mothers had ever experienced abortion. Most of mothers 294(93.9) gave birth within 18 hours while $19(6.1 \%)$ mothers stayed more than 18 hours on labor. Majority of mothers had antenatal care follow-up while $56.4 \%$ had four or above visits. Thirty five (11.2\%) mothers faced the complications during the pregnancy among which the leading cause was pregnancy induced hypertension $17(48.6 \%)$ followed by pre-rupture of fetal membranes $12(34.3 \%)$. Among all deliveries, 36(11.5\%) had experienced complications, of which prolonged labor accounting $13(36.2 \%)$, followed by malpresentation $12(33.3 \%)$ and thirty-one (9\%) women had ever experienced abortion. About onset of labour, 305(97.2\%) were spontaneous and thirty five (11.2\%) mothers gave birth via caesarean section (Table 2).

\begin{tabular}{|c|c|c|}
\hline Variables & Frequency & Percent \\
\hline Gravidity (N=313) & & \\
\hline Primigravida & 223 & 28.8 \\
\hline Multigravida & 71.2 \\
\hline Ever Had Abortion(N=313) & & \\
\hline
\end{tabular}




\section{Journal of Gynecology and Women's Health}

\begin{tabular}{|c|c|c|}
\hline No & 244 & 78 \\
\hline Yes & 69 & 22 \\
\hline \multicolumn{3}{|l|}{ Duration of Labor(N=313) } \\
\hline$\leq 18$ hours & 294 & 93.9 \\
\hline$>18$ hours & 19 & 6.1 \\
\hline \multicolumn{3}{|l|}{ ANC Follow Up(n=313) } \\
\hline No & 26 & 8.3 \\
\hline Yes & 287 & 91.7 \\
\hline \multicolumn{3}{|l|}{ Pregnancy Complication $(\mathrm{N}=313$ ) } \\
\hline No & 278 & 88.8 \\
\hline Yes & 35 & 11.2 \\
\hline \multicolumn{3}{|l|}{ Types of Complication(N=35) } \\
\hline Pregnancy induced Hypertension & 17 & 48.6 \\
\hline Antepartum hemorrhage & 6 & 17.1 \\
\hline Pre-rupture of fetal membranes & 12 & 34.3 \\
\hline \multicolumn{3}{|l|}{ Onset of Labor ( $N=313)$} \\
\hline Spontaneous & 305 & 97.4 \\
\hline Induction & 8 & 2.6 \\
\hline \multicolumn{3}{|l|}{ Mode of Delivery $(n=313)$} \\
\hline Normal Vaginal Delivery & 248 & 79.2 \\
\hline Operative vaginal & 30 & 9.6 \\
\hline Caesarean delivery & 35 & 11.2 \\
\hline \multicolumn{3}{|l|}{ Complication During Labour(N=313) } \\
\hline No & 277 & 88.5 \\
\hline Yes & 36 & 11.5 \\
\hline \multicolumn{3}{|l|}{ Type of Labor Complication $(\mathrm{N}=36)$} \\
\hline Prolonged labour & 13 & 36.2 \\
\hline Malpresentation & 12 & 33.3 \\
\hline Obstructed labour & 4 & 11.1 \\
\hline Others & 7 & 19.4 \\
\hline
\end{tabular}

Regarding medical illness, 26(8.3\%) mothers have a chron- during the pregnancy and, in 27(8.6\%) of mothers, the hemogloic medical problem. According to reports in the mothers' card, bin level was less than 11gm/dl (Table 3).

$7(2.2 \%)$ mothers were HIV positive, $18(5.8 \%)$ diagnosed UTI

Table 3: Medical factors among women who gave birth at Butajira hospitals from Feb 1- 2018 to Feb. 1-2019.

\begin{tabular}{|c|c|c|}
\hline Variables & Frequency & Percent \\
\hline Chronic Illness & & 8.3 \\
\hline Yes & 26 & 91.7 \\
\hline No & 287 & 97.8 \\
\hline HIV Status & 306 & 2.2 \\
\hline Negative & 7 & 94.2 \\
\hline Positive & & \\
\hline UTIs During Pregnancy & 295 & 5.8 \\
\hline Negative & 18 & \\
\hline Positive & & \\
\hline Hemoglobin Level & 286 & 91.4 \\
\hline$\geq 11 \mathrm{~g} / \mathrm{dl}$ & 27 & \\
\hline$<11 \mathrm{~g} / \mathrm{dl}$ & & \\
\hline
\end{tabular}




\section{Prevalence of Adverse Birth Outcomes}

Table 4: Prevalence of adverse birth outcome among mothers who gave birth at Butajira hospitals from Feb 1- 2018 to Feb. 1-2019.

\begin{tabular}{|c|c|c|}
\hline Variables & Frequency & Percentage \\
\hline \multicolumn{3}{|l|}{ Sex of Fetus } \\
\hline Female & 352 & 84.4 \\
\hline Male & 70 & 16.6 \\
\hline \multicolumn{3}{|l|}{ Fetal Status } \\
\hline Alive & 302 & 96.5 \\
\hline Still birth & 11 & 3.5 \\
\hline \multicolumn{3}{|l|}{$\begin{array}{l}\text { Birth Weight of Live Birth Baby } \\
\qquad(\mathrm{N}=302)\end{array}$} \\
\hline Normal birth weight(2500-4000gm) & 275 & 91.1 \\
\hline Low birth weight $(<2500 \mathrm{gm})$ & 27 & 8.9 \\
\hline \multicolumn{3}{|l|}{ Gestational Age $(\mathrm{N}=313)$} \\
\hline Term (37-42wks) & 293 & 93.6 \\
\hline $\operatorname{Preterm}(<37 \mathrm{wks})$ & 20 & 6.4 \\
\hline \multicolumn{3}{|l|}{ Congenital } \\
\hline No & 295 & 94.2 \\
\hline Yes & 18 & 5.8 \\
\hline \multicolumn{3}{|l|}{ Adverse Birth Outcome } \\
\hline No & 256 & 81.8 \\
\hline Yes & 57 & 18.2 \\
\hline
\end{tabular}

The prevalence of adverse birth outcome was 57(18.2\%). Out of these, $27(8.9 \%)$ live birth were low birth weight, $20(6.4 \%)$ preterm birth, $11(3.5 \%)$ stillbirth, and $18(5.8 \%)$ babies were with visible congenital malformation, respectively (Table 4).

\section{Factors of Adverse Birth Outcome}

In multiple logistic regression analysis, mothers aged 35 and above, being rural residence, complication during the pregnancy and history of abortion were found to be risk factors of adverse birth outcome. Mothers aged 35 and above were nearly nine times more likely experienced adverse birth outcome to compared to women in the age group between 20-34 years old $[\mathrm{AOR}=8.7 ; 95 \% \mathrm{CI}(3.1,24.0)]$. The occurrence of complication during pregnancy was nearly thirteen times more likely to have an adverse birth outcome than their counterparts [AOR=12.9, 95\% CI $(4.8,35.2)]$.

Also, mothers who were encountered pregnancy complication during current pregnancy were nearly 3 times more likely to deliver still birth compare to their counterparts (AOR=2. 9, $95 \%$ CI $(1.2,6.9)$. Similarly, mothers who lived in rural residence were three or more times more likely to encounter adverse birth outcomes compared to who was living in Urban residence $[\mathrm{AOR}=3.2,95 \% \mathrm{CI}(1.5,7.7)]$. In addition, those mothers who had a history of abortion were more than two times $[\mathrm{AOR}=2$. $4,95 \%$ CI $(1.1,5.4)]$ more likely to experienced adverse birth outcomes than their counterparts (Table 5).

Table 5: Factors of Adverse birth outcome among among mothers who gave birth at Butajira hospitals from Feb 1- 2018 to Feb. 1-2019.

\begin{tabular}{|c|c|c|c|c|}
\hline \multirow{2}{*}{ Variables } & \multicolumn{2}{|c|}{ Adverse Birth Outcome } & \multirow{2}{*}{$\operatorname{COR}(95 \% \mathrm{CI})$} & \multirow{2}{*}{ AOR $(95 \% \mathrm{CI})$} \\
\hline & No & Yes & & \\
\hline \multicolumn{5}{|l|}{ Age Group } \\
\hline$<20$ & 32 & 1 & $.2(.02,1.5)$ & $1(.09,10.9)$ \\
\hline $20-34$ & 215 & 34 & 1 & 1 \\
\hline 35 and above(ref.) & 9 & 22 & $15.5(6.6,36.5)^{*}$ & $8.7(3.1,24.5)^{* *}$ \\
\hline \multicolumn{5}{|l|}{ Residence } \\
\hline Urban(ref) & 197 & 17 & 1 & 1 \\
\hline Rural & 59 & 40 & $7.9(4.2,15.0)^{*}$ & $3.2(1.5,7.7)^{* *}$ \\
\hline \multicolumn{5}{|l|}{ Gravidity } \\
\hline Primi(ref.) & 86 & 4 & 1 & 1 \\
\hline Multi & 170 & 53 & $6.7(2.35,19.1)^{*}$ & $3.0(.8,11.4)$ \\
\hline \multicolumn{5}{|l|}{ History of Abortion } \\
\hline No(ref.) & 213 & 31 & 1 & 1 \\
\hline Yes & 43 & 26 & $4.2(2.245,7.7)^{*}$ & $2.4(1.1,5.4)^{*}$ \\
\hline \multicolumn{5}{|l|}{ Mode of Delivery } \\
\hline Normal Vaginal Delivery(ref.) & 212 & 36 & 1 & 1 \\
\hline Instrumental delivery & 25 & 5 & $1.2(.4,3.3)$ & $1.1(.3,4.2)$ \\
\hline Caesarean Section (C/S) & 19 & 16 & $5(2.3,10.5) *$ & $2.3(.8,6.9)$ \\
\hline \multicolumn{5}{|l|}{ Complications During Pregnancy } \\
\hline No(ref.) & 243 & 35 & 1 & 1 \\
\hline Yes & 13 & 22 & $11.7(5.4,15.4))^{*}$ & $12.9(4.8,35.2)^{* *}$ \\
\hline
\end{tabular}




\section{Discussion}

The overall prevalence of adverse birth outcome was $18.2 \%$. The prevalence of adverse birth outcome found in the present study is relatively similar to that reported in the Hospital based study conducted at Hawassa and Nigeria were 18.3\% and 19\% respectively $(29,40)$. However, this study found out a lower prevalence of adverse birth outcome compared to other Hospital based study in Gondor, Hossana, Tigray, and Dessie where 23\%, $24.5 \%, 22.6 \%$ and $32.5 \%$ respectively [31-34]. This variation may be due to difference in study design, study setting, sociocultural status, maternal and newborn health care services and various interventions undertaken between these study times.

The study showed that mothers with history abortion was found at more risk of adverse birth outcome than those who have a history of bad obstetrics history. This finding was similar to a previous study done in Brazil [24]. Reason for such similarity cannot be clarified. In this study, mothers aged 35 or above was one of the risk factors for adverse birth outcome. This finding was almost found as a universal fact, the mother's age increases the risk of obstetric complications also increases. Similar finding was also reported from the study done in house [29] which revealed that mothers aged.

As revealed by the present study, pregnancy complication was found to have significant association with an adverse birth outcome. Pregnancy complications that contributed to adverse birth outcome in this study may have resulted from insufficient antenatal care follow-up, and pregnancy related complications decreased blood perfusion to uterus, which lead to low birth weight, preterm delivery, and even fetal death. This finding was almost found to be a universal fact and has been revealed in many studies [25, 28, 31-33].

This study showed that mothers who have a history of abortion were at a higher risk of having an adverse outcome compared to mothers who had no bad obstetric history. Similar findings were also reported from the study done in Brazil, which revealed that mothers who had a bad obstetric history were more likely to experience adverse birth outcome compared with those mothers who had no bad obstetrics history [29].

Moreover, this study found that mothers who have been living in rural residence was associated with adverse birth outcome. It would have been more ideal, in developing country like Ethiopia maternal health care service distribution were not equal in the urban and rural residence. Also, the awareness of the rural mothers about maternal care services is low compared to the urban mothers. This is again supported by a research done in Brazil [24], and Gambian [25]. In this study, data were collected from mothers card, in which some important variables were missing these highlighted as risk factors of adverse birth outcome in different studies. Regarding dependent variable, different authors were defined in different way probable to scientifically under or over classifying adverse birth outcome is highly questionable [40].

\section{Conclusion}

Adverse birth outcome is quite common in the study area. Mothers aged 35 and above, being rural residence, pregnancy complication, and history of abortion were factors of adverse birth outcome. Health education during antenatal care follow-up of pregnant mothers about the need to attend maternity ward early, as soon as possible in labor especially who are history of abortion, and pregnancy complication recommended in order to reduce adverse birth outcome. In addition, further study was recommended in the study area to include some vital variables and to develop an intervention plan.

\section{Supporting Information}

$$
\begin{aligned}
& \text { a) S1. SPSS } \\
& \text { b) S2. Check list }
\end{aligned}
$$

\section{Authors' Contributions}

Ritbano Ahmed Abdo participated in conceptualization of the study design, participated in data collection, analyzed the data, and interpretation, and also drafted the manuscript. Lealem Zerihun Birhanu, Dejene Agero Defara conceived, designed, wrote the study, participated in data collection, and interpreted the data, and revised subsequent draft of the paper. Hassen Mossa Halil and Biruk Assefa Kebede participated in conceptualization of the study design and participated in data collection. All authors read and approved the final manuscript.

\section{Acknowledgement}

We would like to thank data collectors, supervisors, Wachemo University and staffs of the study facilities.

\section{References}

1. UN-DESE Population Division (2017) United Nations Inter-agency Group for Child Mortality Estimation, Switzerland.

2. WHO, UNICEF, World Bank group, united nation (2018) Levels \& Trends in Child Mortality Report 2018, Avenue Appia 20, 1211 Geneva 27, Switzerland.

3. WHO, UNICEF, World Bank, UN-DESE Population Division (2015) Levels and Trends in Child Mortality.

4. Shaun Odell Md (2017) Global burden of neonatal disease: caring for the world's most vulnerable patients 2017 newborn pediatric critical care conference.

5. World Health Organization (1997) Basic Newborn Resuscitation: A Practical Guide. World Health Organization, Geneva, Switzerland, p. 32.

6. Institute of Medicine (2007) Preterm Birth: Causes, Consequences, and Prevention. In: Behrman RE, Butler AS (.Eds), The National Academies Press, Washington DC, USA.

7. Dutta's DC (2013) Textbook of Obstetrics Including Perinatology and Contraception. In: $\left(7^{\text {th }}\right.$ edn), Jaypee Brothers Medical Publishers (P) Ltd, India.

8. Howson CP, Kinney MV, Lawn JE (2012) Born too soon, The global action report on preterm birth. WHO, Geneva, Switzerland.

9. Riyami NA, Al-Ruheili I, Al-Shezawi F, Al-Khabori M (2013) Extreme Preterm Premature Rupture of Membranes: Risk Factors and Feto Maternal Outcomes. Oman Med J 28(2): 108-111. 
10. Moster D, Wilcox AJ, Vollset SE, Markestad T, Lie RT, et al. (2010) Cerebral Palsy among Term and Postterm Births. JAMA 304(9): 976-982.

11. Wapner RJ, Miodovnik M, Landon MB, Spong CY, Lai Y, et al. (2009) Timing of elective repeat cesarean delivery at term and neonatal outcomes. New England Journal of Medicine 360(2): 111-120.

12. Mathews TJ, MacDorman MF (2008) Infant mortality statistics from the period linked birth/infant death data set. National Vital Statistics Reports 57(2).

13. Clark SL, Miller DD, Belfort MA, Dildy GA, Frye DK, et al. (2009) Neonatal and maternal outcomes associated with elective term delivery. Am J Obstet Gynecol 200(2): 156 e1-4.

14. Islam MM (2015) The Effects of Low Birth Weight on School Performance and Behavioral Outcomes of Elementary School Children in Oman. Oman Med J 30(4): 241-251.

15. Nakamuro M, Uzuki Y, Tomohiko I (2013) The effects of birth weight: Does fetal origin really matter for long-run outcomes? Economics Letters 121(1): 53-58.

16. Drotar D, Hack M, Taylor G, Schluchter M, Andreias L, et al. (2006) The Impact of Extremely Low Birth Weight on the Families of School-Aged Children. Pediatrics 117(6): 2006-2013.

17. Sharma M, Sunita M (2013) Maternal risk factors and consequences of low birth weight in Infants. IOSR Journal Of Humanities And Social Science 13(4): 39-45.

18. Nuzum D, Meaney S, O'Donoghue K (2018) The impact of stillbirth on bereaved parents: A qualitative study. Plos One 13(1): e0191635.

19. Samantha M, Cacciatore J (2017) The psychological, social, and economic impact of stillbirth on families. Seminars in Fetal and Neonatal Medicine 22(3): 129-134.

20. Cacciatore J, Bushfield S (2007) Stillbirth: The Mother's Experience and Implications for Improving Care. J Soc Work End Life Palliat Care 3(3): 59-79.

21. WHO (2018) Maternal and Child Epidemiology Estimation Group (MCEE) 2018. Estimates for child causes of death 2000-2016.

22. Martin JA, Hamilton BE, Sutton PD, Ventura SJ, Mathews TJ, et al. (2010) Births: Final Data for 2007. Natl Vital Stat Rep 58(24): 1-85.

23. Hodek JM, Schulenburg VDJM, MittendorfT (2011) Measuring economic consequences of preterm birth- Methodological recommendations for the evaluation of personal burden on children and their caregivers. Health Econ Rev 1(1): 6.

24. Juliana C (2016) Adverse pregnancy outcomes and maternal urban or rural residence at birth in Brazil. J Obstet and Gynecology 42: 496-504.

25. Jammeh A, Sundry J, Vangen S (2011) Maternal and obstetric risk factors for low birth weight and preterm birth in rural Gambia: a hospital based study of 1579 delivers. Open J Obstetrics and Gynecol 1(3): 94-103.
26. Honein MA, Kirby RS, Meyer RE, Xing J, Skerrette NI, et al. (2009) The association between major birth defects and preterm birth. Matern Child Health J 13(2): 164-175.

27. Goldenberg RL, Culhane JF (2007) Low birth weight in the United States. Am J Clin Nutr 85(2): 584S-590S.

28. Chen Y, Li G, Ruan Y, Zou L, Wang X, et al. (2013) An epidemiological survey on low birth weight infants in China and analysis of outcomes of full-term low birth weight infants. BMC Pregnancy Childbirth 13: 242.

29. Tsegaye B, Kassa A (2017) Prevalence of adverse birth outcome and associated factors among women who delivered in Hawassa town governmental health institutions, south Ethiopia, in 2017. Reprod Health15(1): 193.

30. Kaur J, Kaur K (2012) Obstetric Complications; Primiparity versus Multiparity in India. Eur J Exp Biol 2: 1462-1468.

31. Adane AA, AyeleT A, Ararsa LG, Bitew BD, Zeleke BM, et al. (2014) Adverse birth outcomes among deliveries at Gondor University Hospital, Northwest Ethiopia. BMC pregnancy and childbirth 14: 90.

32. Abdo RA, Tesso FY (2016) Prevalence and associated Factors of Adverse birth Outcomes among Women attended Maternity Ward at Negest Elene Mohammed Memorial General Hospital in Hosanna, SNNPR, Ethiopia. J Women's Health Care 5(4).

33. Tesfay A, Abera H, Brhane G (2017) Assessment of Magnitude and Associated Factors of Adverse Birth Outcomes among Deliveries at Suhul Hospital Shire, Tigray, Ethiopia From September, 2015 to February, 2016. Biomed J Sci\& Tech Res 6(1): 1-10.

34. Cherie N, Mebratu A (2017) Adverse birth outcome and Associated Factors among Delivered mothers in Dessie Referal Hospital, North East Ethiopia. Journal women's health reproductive medicine 1: 1-4.

35. (2014) Federal Democratic Republic of Ethiopia Ministry of Health. National Reproductive Health Strategy 2014-2018.

36. Lawn JE, Blencowe $\mathrm{H}$, Waiswa $\mathrm{P}$ (2016) Stillbirths: rates, risk factors, and acceleration towards 2030. Lancet 387(10018): 587-603.

37. (2017) Ethiopia Demographic and Health Survey 2016. Addis Ababa, July 2017. Central Statistical Agency, FMOH, ICF International, Maryland, USA.

38. Deribew A, Tessema GA, Deribe K, Melaku YA, Lakew Y et al. (2016) Trends, causes, and risk factors of mortality among children under 5 in Ethiopia, 1990-2013: findings from the Global Burden of Disease Study 2013. Population Health Metrics 14: 42.

39. Mengesha HG, Sahle BW (2017) Cause of neonatal deaths in Northern Ethiopia: a prospective cohort study. BMC Public Health 17(1): 62.

40. Agarwal A, Agarwal VK, Agarwal P, Chaundhary V (2011) Prevalence and determinants of low birth weight among institutional deliveries. Ann Nigerian Med 5(2): 48-45. 
CC This work is licensed under Creative BY DOI: 10.19080/JGWH.2019.15.555920

\section{Your next submission with Juniper Publishers} will reach you the below assets

- Quality Editorial service

- Swift Peer Review

- Reprints availability

- E-prints Service

- Manuscript Podcast for convenient understanding

- Global attainment for your research

- Manuscript accessibility in different formats

( Pdf, E-pub, Full Text, Audio)

- Unceasing customer service

Track the below URL for one-step submission https://juniperpublishers.com/online-submission.php 